\title{
What Is the Early/Mid-term Survivorship and Functional Outcome After Bernese Periacetabular Osteotomy in a Pediatric Surgeon Practice?
}

\author{
George Grammatopoulos FRCS (Tr \& Orth), DPhil, Jeremy Wales MBBS, \\ Alpesh Kothari MSc, MRCS, Harinderjit S. Gill BEng, DPhil, \\ Andrew Wainwright FRCS (Orth), MSc, \\ Tim Theologis MSc, PhD, FRCS
}

Published online: 12 June 2015

(C) The Association of Bone and Joint Surgeons $\mathbb{R} 2015$

\begin{abstract}
Background The Bernese periacetabular osteotomy (PAO) is a recognized joint-preserving procedure. Achieving joint stability without creating impingement is important, but the orientation target that best balances these sometimes competing goals has not yet been clearly defined. Moreover, the learning curve of this challenging procedure has not been described.

Questions/purposes The purposes of this study were (1) to determine the 10-year survivorship and functional outcome after Bernese PAO in a single-surgeon series; (2) to review which patient, surgical, and radiographic factors might predict
\end{abstract}

Each author certifies that he or she has no commercial associations (eg, consultancies, stock ownership, equity interest, patent/licensing arrangements, etc) that might pose a conflict of interest in connection with the submitted article.

All ICMJE Conflict of Interest Forms for authors and Clinical Orthopaedics and Related Research ${ }^{\mathbb{R}}$ editors and board members are on file with the publication and can be viewed on request.

Clinical Orthopaedics and Related Research ${ }^{\mathbb{R}}$ neither advocates nor endorses the use of any treatment, drug, or device. Readers are encouraged to always seek additional information, including FDAapproval status, of any drug or device prior to clinical use.

Each author certifies that his or her institution approved the human protocol for this investigation, that all investigations were conducted in conformity with ethical principles of research, and that informed consent for participation in the study was obtained.

This work was performed at the Nuffield Orthopaedic Centre, Oxford, UK.

G. Grammatopoulos, J. Wales, A. Kothari, A. Wainwright,

T. Theologis $(\varangle)$

Nuffield Orthopaedic Centre, Windmill Road,

Oxford OX3 7LD, UK

e-mail: tim.theologis@ouh.nhs.uk

H. S. Gill

University of Bath, Bath, UK outcome after the procedure; and (3) to define the learning curve for target acetabular correction.

Methods The first 68 PAOs performed for symptomatic hip dysplasia were retrospectively evaluated. None have been lost to followup with followup less than 2 years. Endpoints for the lost to followup $(n=2)$ are at the time of when last seen. During the study period, the same surgeon performed 562 pelvic osteotomies (including Salter, Pemberton, Dega and Chiari) and 64 shelf acetabuloplasties. Bernese PAO was used only for symptomatic dysplasia (center-edge angle $<25^{\circ}$ and nonhorizontal acetabular roof) in developmentally mature hips without evidence of major joint incongruence or subluxation. Most patients were female ( $\mathrm{n}=49$ [60 hips, 88\%]); mean age at operation was 25 years (SD 7). Sixteen hips had previous hip procedures. The study's mean followup was 8 years (range, 2-18 years). Patient-reported functional outcome was obtained using the WOMAC score (best-worst: 0 96). Radiographic parameters of dysplasia (acetabular index $[\mathrm{AI}]$, center-edge angle [CEA], congruency, Tönnis grade, and joint space) were evaluated from preoperative and postoperative radiographs using computer software.

Results The 10-year survival rate was 93\% (95\% confidence interval $[\mathrm{CI}], 82 \%-100 \%$ ); four patients underwent further surgery to the hip in the study period. The mean WOMAC was 12 (range, 0-54). Factors that influenced survival included joint congruency (100\% versus $78 \%$; 95\% CI, 61\%-96\%; $\mathrm{p}=0.03$ ) and acetabular orientation correction achieved $\left(\mathrm{AI}_{\text {postoperative }}<15^{\circ}[100 \%\right.$ versus 65\%; 95\% CI, 43-88; $\mathrm{p}<0.001]$ and $\mathrm{CEA}_{\text {postoperative }} 20^{\circ}$ to $40^{\circ}[100 \%$ versus $\left.71.9 \% ; 52.8-100 ; \mathrm{p}<0.001]\right)$. Better WOMAC scores were seen if postoperative AI $<15^{\circ}$ (7 versus $25, \mathrm{p}=0.005)$ and CEA between $20^{\circ}$ and $40^{\circ}(7$ versus $23, \mathrm{p}=0.005)$ were achieved. The chances of obtaining acetabular correction within this range improved after the $20^{\text {th }}$ procedure ( $30 \%$ versus $70 \%, \mathrm{p}=0.008$ ). 
Conclusions This study reports excellent results after Bernese PAO in the hands of an experienced pediatric hip surgeon. We advocate cautious correction of the acetabular fragment. Future studies should concentrate on how to determine what the optimal target is and how to achieve it intraoperatively, minimizing the learning curve associated with it.

Level of Evidence Level III, therapeutic study.

\section{Introduction}

Acetabular dysplasia may be a risk factor for the development of osteoarthritis (OA) $[6,16,17,20,28]$. In an attempt to delay joint degeneration in patients with acetabular dysplasia, it has been considered logical to surgically correct morphological abnormalities that might predispose a symptomatic hip to the development of arthritis. In doing so, surgeons aim to improve biomechanics of the hip and delay, or prevent, joint degeneration. Both acetabuloplasty [4] and acetabular reorientation procedures (Bernese [5], triple [21], Birmingham [11]) have been described as joint-preserving surgical options in patients with symptomatic, dysplastic hips. Among those, the Bernese periacetabular osteotomy (PAO), first described in 1988, has been the one most widely used.

Outcome after Bernese PAO has only been reported by the innovator and a limited number of high-volume, specialist surgeons across the world (Table 1) $[3,8,10,14,15,22,24$, $26,27]$. This reflects the complexity of the procedure but can also, potentially, create publication biases; hence, more reports are needed. Ten-year outcome postsurgery is reported to be between $75 \%$ and $90 \%$. Factors shown to affect outcome include: age, severity of hip dysplasia, degree of OA presurgery, hip congruency, and achieved correction. Achieving optimal joint stability without creating impingement has also been reported to improve survival [1]. However, the orientation target that best balances these sometimes competing goals has not yet been clearly defined. Furthermore, what the learning curve is for achieving one's target reliably has not been described either.

The aims of this study were (1) to determine the 10-year survivorship and functional outcome after Bernese PAO in a single-surgeon series; (2) to review which patient, surgical, and radiographic factors might predict outcome after the procedure; and (3) to identify what the learning curve is to reliably achieve target acetabular correction.

\section{Patients and Methods}

This is a retrospective, institutional review board-approved, case series study of the senior author's (TT's) initial experience with Bernese PAO. This surgeon is a pediatric surgeon at the Nuffield Orthopaedic Centre (Oxford, UK) with an interest in young adult hip pathology. The surgeon began using the Bernese PAO in October 1996, and from that date through January 2013, he performed 68 Bernese PAOs in 57 patients, which formed this study's cohort. Two patients (hips) were lost by followup but were included in survivorship analysis up to when last seen. Over the same period, the senior author performed a total of 562 pelvic osteotomies (including Salter's, Pemberton's, Dega's, and Chiari's) and 64 shelf acetabuloplasties. The indication for a Bernese PAO was the presence of a symptomatic, dysplastic (center-edge angle [CEA] $<25^{\circ}$ and nonhorizontal acetabular roof), developmentally mature hip without evidence of major joint incongruence or subluxation. The minimum followup was 2 years and the mean length of followup was 8 years (range, 2-17 years; SD 4). Patients are offered to be followed up annually with clinical and radiographic assessments. All patients in this study, apart from the two lost by followup, had been reviewed within the last 2 years. The lost to followup patients were last reviewed at 3 and 4 years postprocedure, respectively.

All procedures were performed with a modified SmithPetersen approach using the technique previously described by Ganz et al. [5]. After the ischial, pubic, supraacetabular, and retroacetabular osteotomies, a Schanz screw was inserted in the area of the anteroinferior iliac spine and with the aid of laminar spreaders, the acetabular segment was mobilized. Once desired correction was achieved, the fragment was fixed in situ with two or three cannulated, fully threaded, cancellous screws. Desirable correction was primarily an acetabular index of $0^{\circ}$ on the image intensifier, but also considering the resulting acetabular version. Procedures were performed with general and epidural anesthesia. Postoperatively patients were anticoagulated as per hospital protocol (low-molecular-weight heparin) and received physical therapy from the day after the procedure. They were allowed to partially weightbear (up to $25 \%$ body weight) for 6 weeks and gradually increased weightbearing status to full over the next 4 weeks.

The majority of Bernese PAOs were performed in females $(n=60[88 \%])$. The mean age at surgery was 25 years (range, 15-41 years; Table 2). All patients were skeletally mature at the time of operation. Three patients (three hips) had a significant medical history (one athetoid cerebral palsy, one Marfan's syndrome, and one polio). Sixteen hips had previously had some form of treatment for developmental dysplasia of the hip; two had harness treatment as an infant; three had manipulation, closed reduction, and spica cast treatment; two had arthroscopic assessment and débridement for labral pathology; and nine had previous open hip reduction with femoral and/or pelvic osteotomies (six femoral and five pelvic). 
Table 1. Studies reporting on survival, outcome, and predictors of failure after Bernese PAO

\begin{tabular}{|c|c|c|c|c|c|c|}
\hline Study/year & $\begin{array}{l}\text { Osteotomies } \\
\text { (patients) }\end{array}$ & $\begin{array}{l}\text { Age } \\
\text { (years; } \\
\text { range) }\end{array}$ & $\begin{array}{l}\text { Followup } \\
\text { (years; range) }\end{array}$ & $\begin{array}{l}\text { Survival (number } \\
\text { converted to THA) }\end{array}$ & $\begin{array}{l}\text { Functional } \\
\text { outcome } \\
\text { result (range) }\end{array}$ & Prognostic factors \\
\hline $\begin{array}{l}\text { Siebenrock et al. } \\
{[22] / 1999}\end{array}$ & $75(63)$ & $29(13-56)$ & $11(10-14)$ & $\begin{array}{l}10 \text { years: } 85 \% \\
(\mathrm{n}=13[18 \%])\end{array}$ & $\begin{array}{l}\text { Merle d'Aubigné: } \\
16(12-19)\end{array}$ & Grade of OA, age, poor correction \\
\hline $\begin{array}{l}\text { Matta et al. [15]/ } \\
1999\end{array}$ & $66(58)$ & $34(19-51)$ & $4(2-10)$ & $\begin{array}{l}\text { Not reported } \\
(\mathrm{n}=8)\end{array}$ & $\begin{array}{l}17 \% \text { excellent } \\
59 \% \text { good }\end{array}$ & Grade of OA \\
\hline $\begin{array}{l}\text { Trumble et al. [27]/ } \\
1999\end{array}$ & $123(115)$ & $33(14-54)$ & $4(2-10)$ & $\begin{array}{l}\text { Not reported } \\
(\mathrm{n}=7)\end{array}$ & $\begin{array}{l}\text { HHS: } 89 \\
\text { Merle d'Aubigné: } \\
16\end{array}$ & $\begin{array}{l}\text { Preoperative Tönnis grade } \\
\text { Poor correction }\end{array}$ \\
\hline $\begin{array}{l}\text { Kralj et al. [10]/ } \\
\quad 2005\end{array}$ & $26(26)$ & $34(18-50)$ & $12(7-15)$ & $\begin{array}{l}\text { Not reported } \\
(\mathrm{n}=4)\end{array}$ & WOMAC: 30 & $\begin{array}{l}\text { Preoperative Tönnis grade } \\
\text { Postoperative normalized peak } \\
\quad \text { contact stress as per model }\end{array}$ \\
\hline $\begin{array}{l}\text { Clohisy et al. [3]/ } \\
2005\end{array}$ & $16(13)$ & $18(13-32)$ & 4 & $100 \%$ & HHS: 91 & False acetabulum \\
\hline $\begin{array}{l}\text { Steppacher et al. } \\
{[24] / 2008}\end{array}$ & $75(63)$ & $29(13-56)$ & $20(19-23)$ & $\begin{array}{l}10 \text { years: } 85 \% \\
20 \text { years: } 61 \% \\
(n=27)\end{array}$ & $\begin{array}{l}\text { Merle d'Aubigné: } \\
16(10-18)\end{array}$ & $\begin{array}{l}\text { Age } \\
\text { Positive impingement signs } \\
\text { Grade of OA } \\
\text { Insufficient acetabular cover }\end{array}$ \\
\hline $\begin{array}{l}\text { Matheney et al. } \\
{[14] / 2010}\end{array}$ & 135 (109) & $27(10-45)$ & $9(7-11)$ & $\begin{array}{l}5 \text { years: } 96 \% \\
10 \text { years: } 85 \%\end{array}$ & $\begin{array}{l}\text { WOMAC }_{\text {pain }}: 2 \\
\quad(0-16)\end{array}$ & $\begin{array}{l}\text { Age }>35 \text { years } \\
\text { Poor congruency }\end{array}$ \\
\hline $\begin{array}{l}\text { Hartig-Andreasen } \\
\text { et al. [8]/2012 }\end{array}$ & $401(316)$ & $34(13-61)$ & $8(4-12)$ & $\begin{array}{l}12 \text { years: } 75 \% \\
(\mathrm{n}=69[17 \%])\end{array}$ & $\begin{array}{l}\text { WOMAC: } 22 \\
\quad(0-78)\end{array}$ & $\begin{array}{l}\text { Age } \\
\text { Grade of OA } \\
\text { Achieved CEA } \\
\text { Incongruence }\end{array}$ \\
\hline
\end{tabular}

PAO = periacetabular osteotomy; HHS = Harris hip score; OA = osteoarthritis; CEA = center-edge angle.

Table 2. Demographic and surgical data of the cohort

\begin{tabular}{lc}
\hline Parameter & Value (mean [SD, range] or number) \\
\hline Age (years) & $25(7,15-41)$ \\
Body mass index $\left(\mathrm{kg} / \mathrm{m}^{2}\right)$ & $24(3,17-32)$ \\
Gender & \\
Male & $8(14 \%)$ \\
Female & $49(86 \%)$ \\
Diagnosis & $65(96 \%)$ \\
Dysplasia & $3(4 \%)$ \\
Other & \\
Previous surgery & $52(76 \%)$ \\
None & $5(7 \%)$ \\
Closed procedures & $6(8 \%)$ \\
Femoral osteotomy & $5(7 \%)$ \\
Pelvic osteotomy & $2(2 \%)$ \\
Arthroscopy &
\end{tabular}

\section{Outcome Data}

The WOMAC questionnaire [2] and an overall satisfaction survey were sent to all patients. All patients are regularly reviewed. Outcome scores are not obtained in clinic as part of routine practice and hence we had to send the questionnaire by mail to them. Patients who had undergone an arthroplasty procedure since the Bernese PAO were not asked to respond to the WOMAC questionnaire. Mailed questionnaires were addressed to the administrative support department of the unit. The WOMAC consists of 24 questions in three categories quantifying pain, stiffness, and physical activities of daily living (0-96; 0 = best outcome); it is a questionnaire that has previously been used in studies reporting on outcome after PAO [8, 14] and was hence considered most appropriate. Patients with bilateral osteotomies were invited to answer both the questionnaire and survey for each hip. For those patients who did not return the questionnaire (six), survival and functional outcome were established by telephone interview by the lead author (GG) who had not been involved in their care. Fifty-four patients responded to the questionnaire $(84 \%)$. We were able to determine whether patients had required further hip surgery for all but two patients who had emigrated and we were unable to locate them. The latter were treated as survivals up to the time of last followup (successful withdrawals) or as failures thereafter (worst case scenario analysis). 
Radiographic Measurements

Radiographic analysis was performed on preoperative and postoperative AP pelvic radiographs (Table 3). AP radiographs assessed at 6 weeks postoperatively were available for all patients; however, preoperative radiographs were unavailable for the first 21 patients who had their operation before 2004 when the hospital's radiographic records transitioned from film to electronic. All measurements were made using a previously validated Matlab (Matlab R2009b; The MathWorks, Natick, MA, USA) software program (HipMorf) [18]. The software program allowed the users to click on each various, predetermined, anatomical landmarks. Once all the landmarks have been identified, the software then calculated acetabular index (AI) and CEA. Furthermore, preoperative radiographs were assessed for hip congruency, femoral head roundness, joint space width, and the degree of OA according to the Tönnis classification [25]. All assessments were performed by one author (JW), who was not aware of the status of the hip at followup. Interobserver reliability was tested by the second author (GG) assessing 10 preoperative or postoperative radiographs. Interobserver reliability testing was performed using interclass correlation coefficient for scale data and kappa analysis for ordinal data. Excellent interclass correlation was identified between the observers (intraclass correlation coefficient, 0.84-0.99; $\mathrm{p}<0.001$ ).

\section{Analysis}

Failure was defined as conversion to hip arthroplasty. Survival for the whole cohort was established at 10 years with conversion as the endpoint. Survival was also calculated with lost to followup and those who were deemed to have failing PAOs postquestionnaire analysis (WOMAC > 40), treated as failures, estimating the worst case survival.

PAO survival and patient-reported functional outcome were established for different subgroups. Subanalyses were performed dividing the hips based on age at operation ( $<30$ or $\geq 30$ years old), hip congruency and amount of OA preoperatively, and amount of correction achieved postoperatively as per radiographic measurements. Target postoperative radiographic parameters were defined as CEA $20^{\circ}$ to $40^{\circ}$ and $\mathrm{AI} 0^{\circ}$ to $15^{\circ}$. To determine whether a learning curve to the procedure exists, and what that might be, we compared the orientation of the acetabular fragment achieved in the first 20 cases (Group A) with the last 20 cases (Group C) and the group in between (20-48; Group C). The cutoff level of 20 was chosen as a result of its previous reference as an important learning curve threshold in the treatment of dysplastic hips [9] and the Bernese osteotomy by the innovator [22].
Statistical Analysis

Statistical analysis was performed using SPSS (Version 22; IBM, Armonk, NY, USA). Intergroup comparisons of nonnormally distributed scale data were made using nonparametric tests (Mann-Whitney U, Kruskal-Wallis, logrank). Crosstabulation and the chi-square test were used for categorical data. The effect of the learning curve was analyzed as per categorical data using the three groups previously described. Survival analysis taking into account time to conversion to arthroplasty was performed using Kaplan-Meier survival analysis. Significance was considered when $\mathrm{p}<0.05$ was obtained.

\section{Results}

The 10 year-survival was $93 \%$ (95\% confidence interval [CI], 82\%-100\%) (Fig. 1). To date, 64 hips remain preserved, whereas four hips $(6 \%)$ have been converted to hip resurfacing or THA. The mean time to arthroplasty after the Bernese PAO procedure was 7 years (range, 2-17 years). The mean WOMAC score was 12 (range, 0-54). Four hips (three patients) had WOMAC $>40$ and were hence considered as poorly functioning (Table 4). Accounting for lost to followup $(\mathrm{n}=2)$ and poorly functioning hip as failures, the worst case 10 -year survival was 86\% (95\% CI, 76\%-96\%) (Fig. 2). Twelve patients experienced transient neurapraxia of the lateral femoral cutaneous nerve, and 23 patients underwent elective removal of the screws. There were no major nerve complications (transient or permanent) nor any other major surgical or medical complications (eg, nonunion, deep vein thrombosis).

Factors identified to influence 10-year survival included amount of acetabular orientation correction achieved postoperatively $\left(\mathrm{AI}_{\text {postoperative }}<15^{\circ} ; 100 \%\right.$ versus $65 \%$; 95\% CI, 43-88; p < 0.001 and $\mathrm{CEA}_{\text {postoperative }} 20^{\circ}-40^{\circ}$; $100 \%$ versus $71.9 \%$; $52.8-100 ; \mathrm{p}<0.001)$ and hip congruence $(100 \%$ versus $78 \%$; $95 \% \mathrm{CI}, 61 \%-96 \% ; \mathrm{p}=0.03$ ) (Table 5). Functional outcome (WOMAC score) correlated moderately with the postoperative radiographic parameters measured for both AI (rho $=0.5, \mathrm{p}<0.001$ ) and CEA (rho $=0.5, \mathrm{p}<0.001)$ (Fig. 3). Significantly better WOMAC scores were seen with preoperative low Tönnis grade (9 versus $13, \mathrm{p}=0.02)$, joint space $\geq 3 \mathrm{~mm}$ (10 versus $22, \mathrm{p}=$ 0.03 ), hip congruency ( 7 versus $18, \mathrm{p}=0.01$ ), and postoperative $\mathrm{AI}_{\text {postoperative }}$ of $0^{\circ}$ to $15^{\circ}(7$ versus $25, \mathrm{p}=0.005$ ) and $\mathrm{CEA}_{\text {postoperative }}$ between $25^{\circ}$ and $40^{\circ}$ (7 versus $23, \mathrm{p}=$ 0.005). Neither gender (male: 21 [3-34], female: 11 [0$54], \mathrm{p}=0.4)$ nor age younger than 30 years old (11 [0-54] versus 13 [0-44]) was associated with inferior outcome. A previous pediatric surgical intervention was not associated 
Table 3. Radiographic characteristics and measurement of the cohort*

\begin{tabular}{|c|c|}
\hline Characteristic & $\begin{array}{l}\text { Value (mean }[\mathrm{SD} \text {, range }] \\
\text { or number) }\end{array}$ \\
\hline \multicolumn{2}{|c|}{ Acetabular index $\left({ }^{\circ}\right)$} \\
\hline Preoperative & $13(8,2-32)$ \\
\hline Postoperative & $8(9,-11-26)$ \\
\hline \multicolumn{2}{|c|}{ Center-edge angle $\left({ }^{\circ}\right)$} \\
\hline Preoperative & $16(8,1-26)$ \\
\hline Postoperative & $24(9,6-44)$ \\
\hline \multicolumn{2}{|l|}{ Joint space (mm) } \\
\hline Preoperative & $3(2-5)$ \\
\hline Postoperative & $3(2-5)$ \\
\hline \multicolumn{2}{|l|}{ Congruence } \\
\hline Yes & $35(51 \%)$ \\
\hline No & $33(49 \%)$ \\
\hline \multicolumn{2}{|l|}{ Tönnis grade } \\
\hline 0 & $37(54 \%)$ \\
\hline 1 & $22(33 \%)$ \\
\hline 2 & $9(13 \%)$ \\
\hline 3 & 0 \\
\hline \multicolumn{2}{|c|}{ Target AI achieved $\left(<15^{\circ}\right)$} \\
\hline Yes & $46(68 \%)$ \\
\hline No & $22(32 \%)$ \\
\hline \multicolumn{2}{|c|}{ Target CEA achieved $\left(20^{\circ}-40^{\circ}\right)$} \\
\hline Yes & $41(60 \%)$ \\
\hline No & $27(40 \%)$ \\
\hline \multicolumn{2}{|c|}{ Target achieved for both AI and CEA } \\
\hline Yes & $40(59 \%)$ \\
\hline No & $28(41 \%)$ \\
\hline
\end{tabular}

* Of note, no preoperative assessments could be made on 21 patients; $\mathrm{AI}=$ acetabular index; CEA = center-edge angle.

with inferior survival (95\%; 95\% CI, 85\%-100\% versus $87 \%$; 95\% CI, 71\%-100\%; $\mathrm{p}=0.1$ ) nor functional outcome (10 versus $15, \mathrm{p}=0.4)$ (Table 5). The $\mathrm{CEA}_{\text {postoperative }}$ correlated strongly with $\mathrm{AI}_{\text {postoperative }}$ (rho $=0.9, \mathrm{p}<$ 0.001 ), but no other parameter measured. The desired acetabular orientation (for both CEA and AI) was achieved in 40 hips $(59 \%)$.

With increasing experience with the Bernese PAO, a greater proportion of patients had the desired acetabular orientation $\left(\mathrm{AI}_{\text {postoperative }}: 0^{\circ}-15^{\circ}\right.$ and $\mathrm{CEA}_{\text {postoperative }} 20^{\circ}-$ $40^{\circ}$ ) (Group A: 30\%, Group B: 71\%, Group C: 70\%; chi square $\mathrm{p}=0.008)$.

\section{Discussion}

As our understanding of young adult hip pathology improves, it is likely that the demand for joint salvage

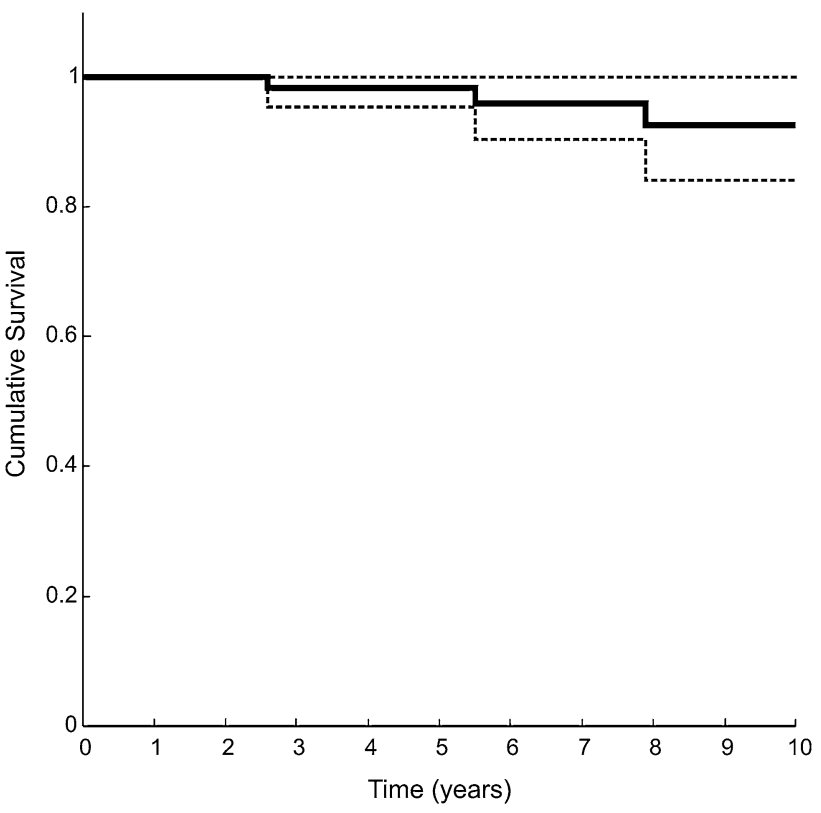

Fig. 1 This is a graph illustrating Kaplan-Meier survivorship curve with conversion to hip arthroplasty as the endpoint for the whole cohort.

Table 4. Radiographic characteristics and measurement of the cohort*

\begin{tabular}{ll}
\hline Parameter & Value (mean [SD, range] or number) \\
\hline WOMAC-pain & $3(3,0-11)$ \\
WOMAC-stiffness & $1(2,0-5)$ \\
WOMAC-physical activity & $8(10,0-41)$ \\
WOMAC-total & $12(14,0-54)$ \\
Satisfaction score & $1(2 \%)$ \\
Disappointed & $1(2 \%)$ \\
Not satisfied & $10(15 \%)$ \\
Fairly satisfied & $42(61 \%)$ \\
Very satisfied &
\end{tabular}

* Of note, no preoperative assessments could be made on 21 patients.

procedures such as the Bernese PAO will increase. Hence, it is prudent to define the outcome after such challenging procedures in different settings around the world. Furthermore, achieving good joint stability without creating impingement is important when performing a Bernese PAO. However, the orientation target that best balances these sometimes competing goals has not yet been clearly defined, and the role of the learning curve as a surgeon begins to use this demanding procedure has, to our knowledge, not been described. This study reflects the experience of a pediatric surgeon with wide experience in pelvic procedures and aimed to (1) describe the 10-year outcome; (2) identify factors that 


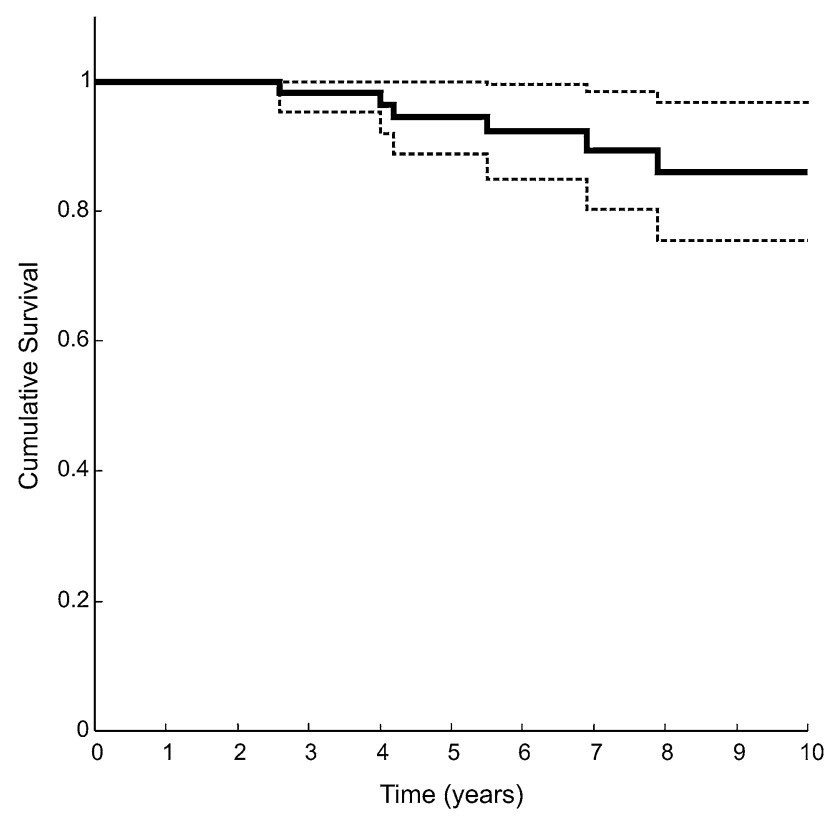

Fig. 2 This is a graph illustrating Kaplan-Meier survivorship curve as the worst case scenario with conversion to hip arthroplasty, poor WOMAC score $(>40)$, and lost to followups treated as endpoints for the whole cohort. influence it; and (3) describe the learning curve in achieving a target orientation.

This study has a number of limitations. First, this is a retrospective, single-surgeon series of early/mid-term followup and hence suffers the inherent weaknesses and biases associated with its nature. Second is the lack of comparative preoperative WOMAC scores, which would have allowed us to make valuable estimations of the overall functional improvement with surgery. However, the operation was not offered unless patients had substantial symptoms and physical limitations. Second, the lack of preoperative radiographs for procedures performed before 2004 reduced our ability to include 21 patients in the preoperative radiographic measurements. Third, the lack of standardized lateral radiographs (false-profile views) and cross-sectional CT imaging pre- and postoperatively prevented us from calculating anterior CEA, pre- and postoperative anteversion/inclination of the acetabulum, and combined anteversion. Such factors have been shown to have an effect on overall satisfaction and outcome. Fourth, there is potential of assessment bias because assessments were made by the surgical team. To reduce

Table 5. The effect of radiographic parameters measured on clinical outcome

\begin{tabular}{|c|c|c|c|c|}
\hline Parameter & $\begin{array}{l}\text { 10-year survival } \\
\text { (worst case) (mean \% }[95 \% \mathrm{CI}]\end{array}$ & $\mathrm{p}$ value & $\begin{array}{l}\text { WOMAC }_{\text {total }} \text { score } \\
\text { (mean }[\mathrm{SD} \text {, range }] \text { ) }\end{array}$ & $\mathrm{p}$ value \\
\hline \multicolumn{5}{|c|}{ Hip congruence } \\
\hline Yes & 100 & 0.03 & $7(7,0-28)$ & 0.01 \\
\hline No & $78(61-96)$ & & $17(17,0-54)$ & \\
\hline \multicolumn{5}{|l|}{ Age } \\
\hline$<30$ & $92(82-100)$ & 0.9 & $11(0-54)$ & 0.1 \\
\hline$\geq 30$ & $94(84-100)$ & & $13(0-44)$ & \\
\hline \multicolumn{5}{|l|}{ Gender } \\
\hline Male & 100 & 0.5 & $21(3-34)$ & 0.4 \\
\hline Female & $92(82-100)$ & & $11(0-54)$ & \\
\hline \multicolumn{5}{|c|}{ Tönnis grade } \\
\hline 0 & $96(89-100)$ & 0.11 & $9(13,0-54)$ & 0.02 \\
\hline 1 and 2 & $79(63-96)$ & & $15(14,0-51)$ & \\
\hline \multicolumn{5}{|l|}{ Joint space } \\
\hline$<3 \mathrm{~mm}$ & $69(37-100)$ & 0.37 & $10(12,0-51)$ & 0.03 \\
\hline$\geq 3 \mathrm{~mm}$ & $90(78-100)$ & & $22(18,3-54)$ & \\
\hline \multicolumn{5}{|l|}{ AI: $<15^{\circ}$} \\
\hline Yes & 100 & $<0.001$ & $7(7,0-28)$ & 0.005 \\
\hline No & $65(43-88)$ & & $25(19,0-54)$ & \\
\hline \multicolumn{5}{|c|}{ CEA: $20^{\circ}-40^{\circ}$} \\
\hline Yes & 100 & 0.04 & $7(7,0-28)$ & 0.005 \\
\hline No & $72(53-100)$ & & $23(19,0-54)$ & \\
\hline \multicolumn{5}{|c|}{ Optimum AI and CEA } \\
\hline Yes & 100 & 0.005 & $7(7,0-28)$ & 0.01 \\
\hline No & $72(53-92)$ & & $22(19,0-54)$ & \\
\hline
\end{tabular}

$\mathrm{CI}=$ confidence interval; $\mathrm{AI}=$ acetabular index CEA = center-edge angle. 

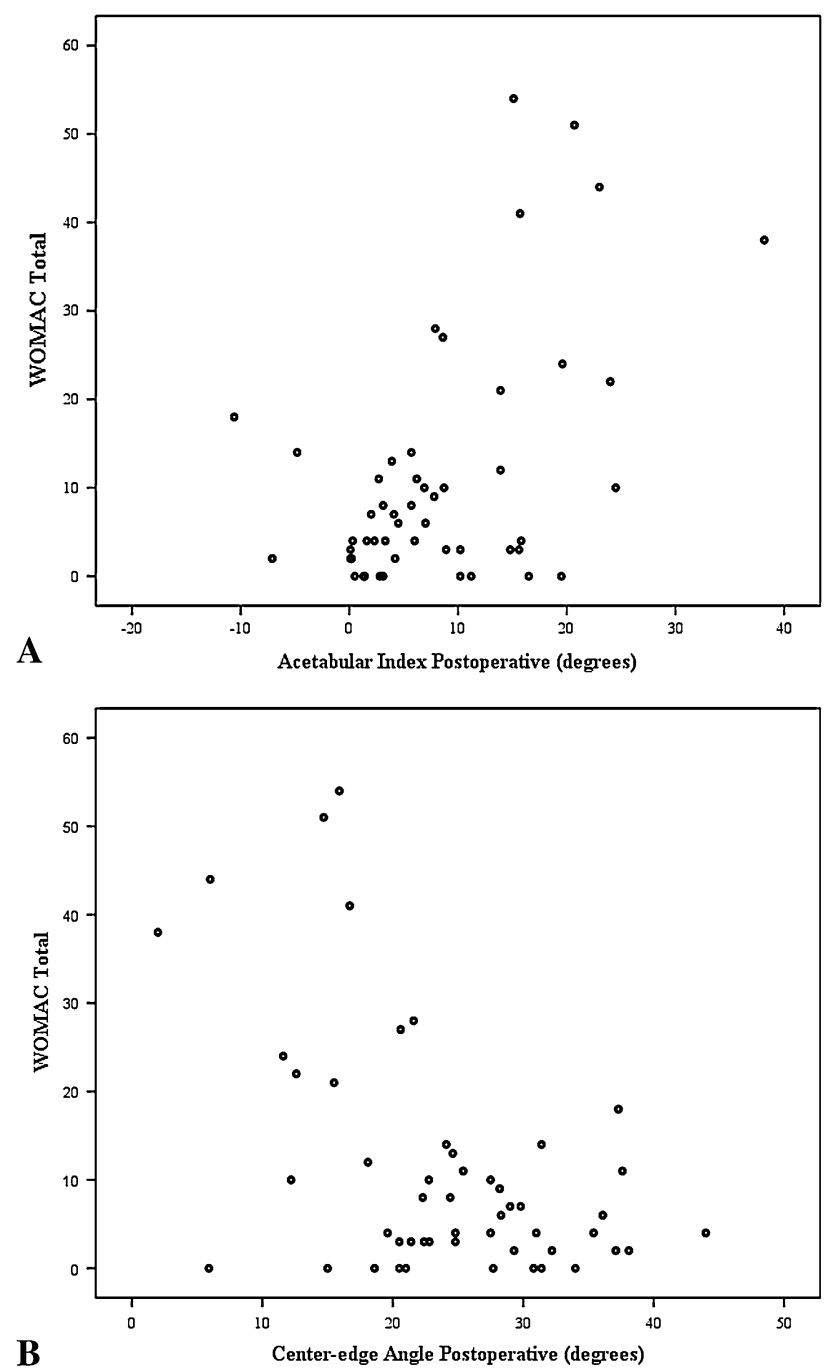

Fig. 3A-B This is two scatterplots illustrating the effect of AI (A) and CEA (B) on WOMAC at followup.

those biases, radiographic assessments were made from a member of the team not involved with analysis and before functional outcome assessments. Furthermore, the author who performed the interviews had not previously looked after the patients. Lastly, as a result of loss to followup and missing data, we were unable to determine procedure survival for two patients and WOMAC scores in six.

The 10-year outcome after the Bernese PAO is excellent and compares well with other reports. Possible reasons for these results is the younger age of the patients (25 years old, SD 7) and the strict criteria used by the senior author when offering the procedure. Patients with nondysplastic, incongruent hips (eg, after Perthes' disease) and patients of older age have been shown to have inferior outcome after the procedure [14]. It is encouraging that most of the patients who responded ( $\mathrm{n}=50$ of 54$)$ reported very good/excellent functional outcome as per the WOMAC questionnaire, and
52 were either very or fairly satisfied with having undergone the procedure. Only three patients had a $\mathrm{WOMAC}_{\text {pain }}$ score more than 10, a criterion used as a failure in previous studies $[8,14]$. Accounting for poorly functioning hips (WOMAC $>$ 40 ) as failures, the 10-year survivorship of $86 \%$ remains a satisfactory outcome and compares well with other studies. Furthermore, no significant complications were encountered after the procedure. In a recent multicenter study, the rate for significant complications was reported to be $6 \%$, emphasizing the importance of expertise and experience required by the surgical team [29].

Both patient and surgical factors affected outcome. Similar to other reports [8, 14], hip morphological parameters innate to the patient (hip congruence) had an effect on outcome. However, timing of presentation and intervention also had an effect. The lower the preoperative Tönnis grade, the better the outcome. Therefore, the lack of radiographic signs of $\mathrm{OA}$ and hip congruence are now essential criteria in the patient selection algorithm used in our practice. The postoperative radiographic parameters, reflecting acetabular orientation achieved, had an effect on survival and functional outcome, emphasizing the importance of surgical experience. Neither age nor gender affected outcome; this is likely the result of lack of statistical power of the study in assessing these factors. Most of our patients were female and young $(72 \%:<30$ years old) with only one being older than 40 years old.

The cautious correction achieved in our cohort is an expected result and accurately reflects the practice and philosophy of the senior author who aimed to avoid overcorrection while aiming to achieve a horizontal acetabular roof; patients with dysplastic hips are at an increased risk of impingement after the osteotomy and if that were to occur, failure risk would significantly rise [1]. There were no patients who had further surgery for impingement nor any stress fractures at the osteotomy sites [13]. We would hence advise to err on the side of caution regarding the amount of correction achieved. Our experience and outcomes, reflecting on such a surgical practice, are satisfactory and would advocate it. Nevertheless, it is likely that with improved technology and preoperative three-dimensional imaging, patient-specific correction will be the target in the future [12]. To our knowledge this is the first study that addresses the learning in achieving the desired acetabular correction target post-PAO. We found a learning curve of 20 procedures resulted in a desired correction being achieved in approximately $70 \%$ of the hips performed after that point. Such results were seen in the hands of an experienced pelvic osteotomy surgeon, having performed $>500$ cases. The difficulties associated with achieving the desired orientation of the acetabulum have been demonstrated in both arthroplasty and joint preservation surgery $[7,8,23]$. Given the significant 
contribution of the radiographic correction to the chances of success after Bernese PAO, refined methods of reducing the learning curve and consistently obtaining optimal orientation are necessary. Furthermore, it emphasizes the importance of such procedures being carried out in specialist centers and such centers having the necessary training opportunities set in place to minimize the learning curve of future hip preservation surgeons [19].

In conclusion, this study reports excellent results after Bernese PAO in the hands of an experienced pediatric hip surgeon. We advocate cautious correction of the acetabular fragment. Future studies should concentrate on how to determine what the optimal target is and how to achieve it intraoperatively, minimizing the learning curve associated with it.

Acknowledgments We thank Zoe Walker for her administrative and supportive role throughout this project.

\section{References}

1. Albers CE, Steppacher SD, Ganz R, Tannast M, Siebenrock KA. Impingement adversely affects 10 -year survivorship after periacetabular osteotomy for DDH. Clin Orthop Relat Res. 2013;471:1602-1614.

2. Bellamy N, Buchanan WW, Goldsmith $\mathrm{CH}$, Campbell J, Stitt LW. Validation study of WOMAC: a health status instrument for measuring clinically important patient relevant outcomes to antirheumatic drug therapy in patients with osteoarthritis of the hip or knee. J Rheumatol. 1988;15:1833-1840.

3. Clohisy JC, Barrett SE, Gordon JE, Delgado ED, Schoenecker PL. Periacetabular osteotomy for the treatment of severe acetabular dysplasia. J Bone Joint Surg Am. 2005;87:254-259.

4. Fawzy E, Mandellos G, De Steiger R, McLardy-Smith P, Benson MK, Murray D. Is there a place for shelf acetabuloplasty in the management of adult acetabular dysplasia? A survivorship study. J Bone Joint Surg Br. 2005;87:1197-1202.

5. Ganz R, Klaue K, Vinh TS, Mast JW. A new periacetabular osteotomy for the treatment of hip dysplasias. Technique and preliminary results. Clin Orthop Relat Res. 1988;232:26-36.

6. Ganz R, Leunig M, Leunig-Ganz K, Harris WH. The etiology of osteoarthritis of the hip: an integrated mechanical concept. Clin Orthop Relat Res. 2008;466:264-272.

7. Grammatopoulos G, Pandit HG, da Assuncao R, McLardy-Smith P, De Smet KA, Gill HS, Murray DW. The relationship between operative and radiographic acetabular component orientation: which factors influence resultant cup orientation? Bone Joint J. 2014;96:1290-1297.

8. Hartig-Andreasen C, Troelsen A, Thillemann TM, Soballe K. What factors predict failure 4 to 12 years after periacetabular osteotomy? Clin Orthop Relat Res. 2012;470:2978-2987.

9. Jain NP, Jowett AJ, Clarke NM. Learning curves in orthopaedic surgery: a case for super-specialisation? Ann R Coll Surg Engl. 2007;89:143-146.

10. Kralj M, Mavcic B, Antolic V, Iglic A, Kralj-Iglic V. The Bernese periacetabular osteotomy: clinical, radiographic and mechanical 715-year follow-up of 26 hips. Acta Orthop. 2005;76:833-840.
11. Kumar D, Bache CE, O'Hara JN. Interlocking triple pelvic osteotomy in severe Legg-Calvé-Perthes disease. J Pediatr Orthop. 2002;22:464-470.

12. Liu L, Ecker T, Schumann S, Siebenrock K, Nolte L, Zheng G. Computer assisted planning and navigation of periacetabular osteotomy with range of motion optimization. Med Image Comput Comput Assist Interv. 2014;17:643-650.

13. Malviya A, Dandachli W, Beech Z, Bankes MJ, Witt JD. The incidence of stress fracture following peri-acetabular osteotomy: an under-reported complication. Bone Joint J. 2015; 97:24-28.

14. Matheney T, Kim YJ, Zurakowski D, Matero C, Millis M. Intermediate to long-term results following the bernese periacetabular osteotomy and predictors of clinical outcome: surgical technique. J Bone Joint Surg Am. 2010;92(Suppl 1):115-129.

15. Matta JM, Stover MD, Siebenrock K. Periacetabular osteotomy through the Smith-Petersen approach. Clin Orthop Relat Res. 1999;363:21-32.

16. Murphy SB, Ganz R, Muller ME. The prognosis in untreated dysplasia of the hip. A study of radiographic factors that predict the outcome. J Bone Joint Surg Am. 1995;77:985-989.

17. Murray RO. The aetiology of primary osteoarthritis of the hip. $\mathrm{Br}$ J Radiol. 1965;38:810-824.

18. Nicholls AS, Kiran A, Pollard TC, Hart DJ, Arden CP, Spector T, Gill HS, Murray DW, Carr AJ, Arden NK. The association between hip morphology parameters and nineteen-year risk of end-stage osteoarthritis of the hip: a nested case-control study. Arthritis Rheum. 2011;63:3392-3400.

19. Peters CL, Beaule PE, Beck M, Tannast M, Jiranek W, Sierra RJ. Report of breakout session: Strategies to improve hip preservation training. Clin Orthop Relat Res. 2012;470:3467-3469.

20. Russell ME, Shivanna KH, Grosland NM, Pedersen DR. Cartilage contact pressure elevations in dysplastic hips: a chronic overload model. J Orthop Surg Res. 2006;1:6.

21. Sen C, Sener N, Tozun IR, Boynuk B. Polygonal triple (Kotz) osteotomy in the treatment of acetabular dysplasia: 17 patients (19 hips) with 4-9 years of follow-up. Acta Orthop Scand. 2003;74:127-132.

22. Siebenrock KA, Scholl E, Lottenbach M, Ganz R. Bernese periacetabular osteotomy. Clin Orthop Relat Res. 1999;363:9-20.

23. Siebenrock KA, Steppacher SD, Albers CE, Haefeli PC, Tannast M. Diagnosis and management of developmental dysplasia of the hip from triradiate closure through young adulthood. J Bone Joint Surg Am. 2013;95:748-755.

24. Steppacher SD, Tannast M, Ganz R, Siebenrock KA. Mean 20year followup of Bernese periacetabular osteotomy. Clin Orthop Relat Res. 2008;466:1633-1644.

25. Tönnis D, Heinecke A. Acetabular and femoral anteversion: relationship with osteoarthritis of the hip. J Bone Joint Surg Am. 1999;81:1747-1770.

26. Trousdale RT, Cabanela ME. Lessons learned after more than 250 periacetabular osteotomies. Acta Orthop Scand. 2003;74:119-126.

27. Trumble SJ, Mayo KA, Mast JW. The periacetabular osteotomy. Minimum 2 year followup in more than 100 hips. Clin Orthop Relat Res. 1999;363:54-63.

28. Wiberg G. Studies on dysplastic acetabula and congenital subluxation of the hip joint. Acta Chir Scand. 1939;58:83.

29. Zaltz I, Baca G, Kim YJ, Schoenecker P, Trousdale R, Sierra R, Sucato D, Sink E, Beaule P, Millis MB, Podeszwa D, Clohisy JC. Complications associated with the periacetabular osteotomy: a prospective multicenter study. $J$ Bone Joint Surg Am. 2014;96:1967-1974. 